\title{
Characteristics and Significance of X-Ray Fluorescence Anomaly of Granite Pegmatite Rare Metal Deposit in Renli, Hunan
}

\author{
Long Zhang \\ Chengdu University of Technology, Chengdu, China \\ Email: 1733262762@qq.com
}

How to cite this paper: Zhang, L. (2021) Characteristics and Significance of X-Ray Fluorescence Anomaly of Granite Pegmatite Rare Metal Deposit in Renli, Hunan. Open Access Library Journal, 8: e7467. https://doi.org/10.4236/oalib.1107467

Received: April 28, 2021

Accepted: May 21, 2021

Published: May 24, 2021

Copyright $\odot 2021$ by author(s) and Open Access Library Inc.

This work is licensed under the Creative Commons Attribution International License (CC BY 4.0).

http://creativecommons.org/licenses/by/4.0/

\section{(c) (i) Open Access}

\begin{abstract}
In the granite pegmatite niobium-tantalum rare metal mining area in Renli, Pingjiang County, Hunan Province, the multi-element X-ray fluorescence measurement of soil was carried out using a handheld X-ray fluorometer on three survey lines passing through known veins. The element combination and amplitude of the mineral-induced X-ray fluorescence anomaly and the spatial correlation between mineral-induced anomalies and the ore body are studied. The results show that there are positive anomalies of $\mathrm{K}, \mathrm{Nb}, \mathrm{Ta}, \mathrm{Rb}$, $\mathrm{Y}$, and negative anomalies (or low-value areas) of $\mathrm{Fe}, \mathrm{Ni}, \mathrm{Zn}$, and $\mathrm{Zr}$ at the outcropping site or above the outcropping projection site. Therefore, the abnormal X fluorescence of the target elements $\mathrm{Nb}, \mathrm{Ta}, \mathrm{Rb}$, and the abnormal multi-element $\mathrm{X}$ fluorescence accumulation ratio of $(\mathrm{Nb}+\mathrm{Ta}+\mathrm{Rb}+\mathrm{Y}) /(\mathrm{Fe}+$ $\mathrm{Ni}+\mathrm{Sr}+\mathrm{Zr}$ ) can be used as the basis for quickly evaluating the minerality of granite pegmatite veins.
\end{abstract}

\section{Subject Areas}

Geology

\section{Keywords}

Granite Pegmatite, Rare Metal Ore, X Fluorescence Measurement, Anomalous Characteristics, Prospecting Significance

\section{1. 引言}

在花岗伟晶岩稀有金属矿勘查区找矿时, 评价伟晶岩脉是否含矿的方法 不少, 但都面临需要取样回实验室做分析(地球化学方法), 或者需要其他方 法配合(传统地球物理方法), 难以在找矿的野外现场快速做出评价与确认。 
一般情况下, 一个伟晶岩稀有金属矿勘查区往往分布着数百条甚至更多的伟 晶岩脉, 然而含矿的伟晶岩脉往往不到 $10 \%$, 这给找矿工作带来不少困难。

针对上述找矿面临的问题, 本文探讨了采用最新一代配置 SDD 探测器的 手持式 X 射线苂光仪, 通过土壤多元素测量解决伟晶岩脉含矿性的现场快速 评价问题。

\section{2. 地质背景}

仁里铌钽矿床位于幕阜山复式岩体西南缘, 大地构造上属于扬子陆块东 南缘江南新元古代造山带中段北缘之湘东北断隆带, 处于扬子陆块与华夏陆 块过渡部位的中生代构造岩浆隆起带, 主要经历了弧盆与岩浆作用阶段、裂 谷盆地阶段、陆表海盆地阶段、陆内构造-岩浆阶段和断陷盆地阶段(图 1)。 大规模成矿多集中在陆块边缘和构造转换带中, 其成矿热动力源于深部, 幕 阜山地区成矿地质条件好, 成矿母岩来自深部, 易形成超大型矿床。区域稀 有金属矿产分布总体呈现出 “北铌钽、东铍、南锂铍铌钽、中铌钽锂、西部 尚未见明显矿化” 的分布规律: 北部以断峰山铌钽矿床为代表; 东部为铍矿 点聚集区; 南部以仁里铌钽矿床、传梓源锂铌钽矿床为代表。整体表现出, 东部以单一的铍矿化为主, 至中部锂铍铌钽多种元素矿化, 北部和南部产出 大型和超大型稀有金属矿床，反映出稀有金属成矿一定的分带性。截止 2017 年 11 月, 仁里矿区已发现伟晶岩脉 140 条, 其中岩体内 95 条, 岩体西南缘 45 条。发现铌钽矿 14 条, 圈定铌钽工业矿体 17 个, 其中岩体内矿体 7 个,

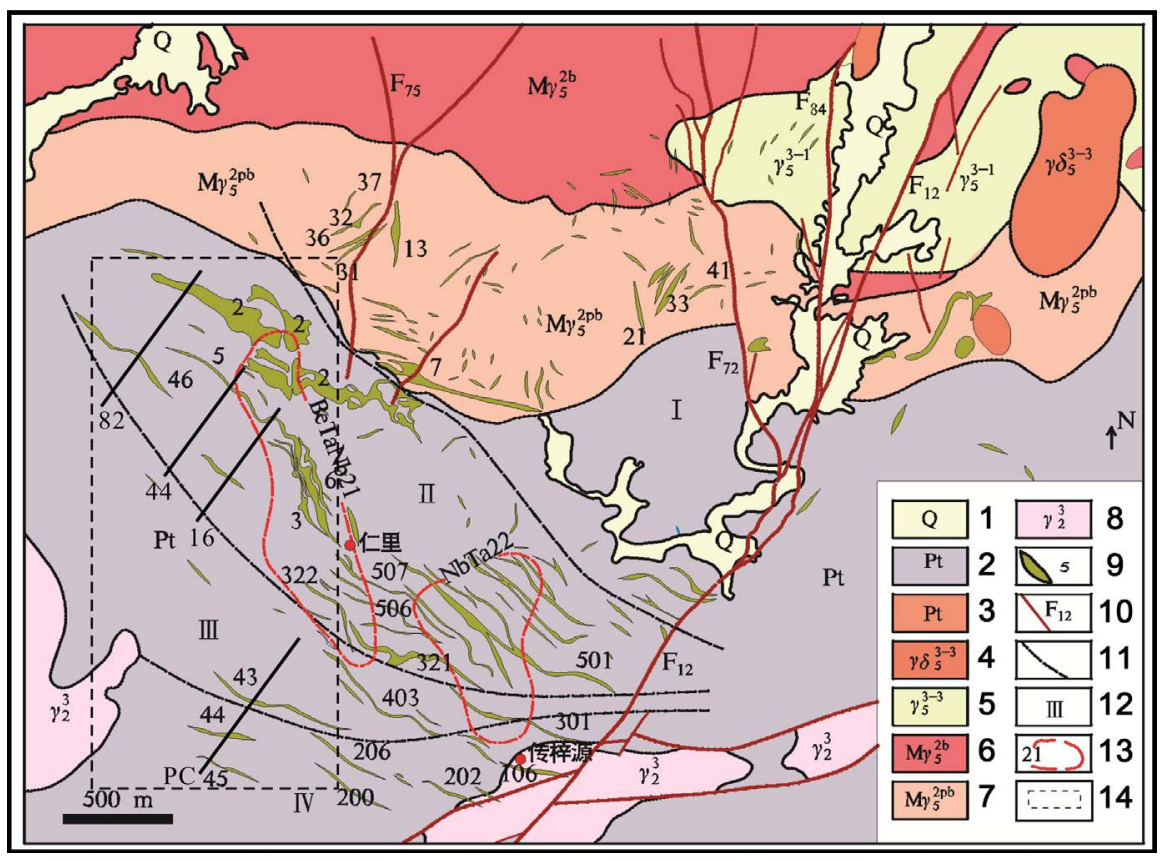

1. 第四系; 2. 元古宙冷家溪群片岩; 3. 细粒花岗闪长岩; 4. 细粒二云母二长花岗岩; 5. 中粒 二云母二长花岗岩; 6. 粗中粒似斑状黑云母二长花岗岩; 7. 粗中粒片麻状黑云母二长花岗岩; 8. 新元古代二云母斜长花岗岩; 9. 伟晶岩脉及其编号; 10. 断裂及其编号; 11. 伟晶岩类型分带 界线; 12. 伟晶岩分带类型; I. 微斜长石型; II. 微斜长石-钠长石型; III. 钠长石型; IV. 钠长 石锂辉石型; 13. 重砂异常晕; 14. X 苂光测区。

图 1. 仁里与传梓源地区地质略图(附 $\mathrm{X}$ 荧光测量部署) 
岩体外矿体 10 个。估算资源量 $\mathrm{Ta}_{2} \mathrm{O}_{5}: 10,791 \mathrm{t}, \mathrm{Nb}_{2} \mathrm{O}_{5}: 14,057 \mathrm{t}, \mathrm{Rb}_{2} \mathrm{O}_{5}: 17,299$ $\mathrm{t}$, 平均品位 $\mathrm{Ta}_{2} \mathrm{O}_{5}: 0.036 \%, \mathrm{Nb}_{2} \mathrm{O}_{5}: 0.047 \%, \mathrm{Rb}_{2} \mathrm{O}_{5}: 0.06 \%$ 。铌锄资源主要 集中在岩体外的 2、3、5、6 号矿脉, 其 $\mathrm{Ta}_{2} \mathrm{O}_{5}$ 资源量占全矿区资源量 $97 \%$ 以 上, 其主要特点为: 矿体密集、规模大、品位高, 且形态简单, 呈层状产出。 成矿物质与成矿类型组合也具有规律性的演化特点, 伟晶岩类型分带对应着 不同类型的矿化, 自岩体向南, 铌钽矿化由强变弱, 锂矿化由弱变强。一般 来说, 伟晶岩规模越大, 分带越完善, 矿化越好。因此规模大、剥蚀程度低 的伟晶岩易形成大的稀有金属矿。这类伟晶岩脉从边部到内部, 大至可分为: 文象带、粗粒白云母钠长石带、糖粒状钠长石带 (及含石榴子石钠长石带) 和 锂云母石英带。绿柱石主要产在粗粒白云母钠长石带; 铌钽铁矿等。铌钽矿 物主要赋存于白云母钠长石带和锂云母石英带中, 呈块状、颗粒状、针状、 片状产出。从外带到内带, $\mathrm{K}$ 含量逐渐减低, $\mathrm{Na}$ 含量逐渐升高, 但在锂云母 石英带因富含锂云母而导致 $\mathrm{K}$ 含量升高, $\mathrm{Na}$ 含量降低; $\mathrm{Nb}$ 、 $\mathrm{Ta}$ 含量在白云 母钠长石带和锂云母石英带含量最高。伟晶岩各分带中矿物及生成顺序存在 一定的规律, 为伟晶岩结晶过程熔体化学成分演化、温压条件、挥发分等差 异及后期交代作用所致, 导致矿物生成顺序亦有先后[1] [2]。

\section{3. 花岗伟晶岩稀有金属矿X菼光特征提取方法}

根据莫塞莱定律, 元素的特征 $\mathrm{X}$ 射线能量与其原子序数的平方成正比。 当选用确定的激发源照射样品时, 会产生样品中某些元素的特征 X 射线。样 品中元素所产生的特征 X 射线的照射量率与该元素的含量成正比。因此, 依 据所测量 X 苂光谱线的能量与照射量率, 可以分别确定被测元素是谁, 其含 量有多少, 这就是 X 苂光方法可以对土壤及岩(矿)石成分进行定性与定量测 定的物理基础。研究工作所用仪器为英国牛津公司生产的 X-MET7500 手持式 $\mathrm{X}$ 射线苂光仪。该仪器是目前国际上最新一代的手持式 $X$ 荧光仪之一, 配置 牛津公司自制的 $45 \mathrm{keV}$ 铑阳极 X 射线管和 SDD 高分辨率探测器, 元素分析 范围可从 19 号元素钾 $(\mathrm{K})$ 到 92 号元素铀(U), 并可同时分析地质样品中 30 种 以上元素含量, 分析检出限从 $\mathrm{n} \times 10^{-6}$ 到 $\mathrm{n} \times 10^{-1}$, 可以快速稳定的进行土壤 样品的快速测量, 能满足研究工作需要。

铌和钽是典型的亲石元素。两者因原子结构相同, 地化性质相近故在自 然作用中密切共生, 并形成极完全的类质同象系列(如铌铁矿 - 钽铁矿族等), 至今还未见有完全不含铌的钽矿物, 或者不含钽的铌矿物。钛、锆、稀土、 铀、钍、铇和锡等由于与铌钽的地球化学性质相近而密切共生。铌钽主要呈 铌铁矿 - 钽铁矿或细晶石等形态产出 [3]。在仁里花岗伟晶岩稀有金属矿区 中, 岩石主要由石英、钾长石、钠长石、白云母组成; 主要矿物有微斜长石、 石英、白云母、石榴子石、绿柱石、黑电气石、锂电气石、黄玉、铯榴石锂 云母和铌钽矿等。铌钽铁矿主要赋存于伟晶岩的中粗粒的钠长石带、钠长石 - 白云母、钠长石 - 白云母 - 石英带及白云母 - 石英带, 锂矿主要赋存于锂 云母及锂电气石中 $[4]$ 。因而, 我们可以通过矿物中元素组分及含量的不同, 以及共生元素组分及含量的不同, 应用手持式 $X$ 荧光测量仪在现场快速的区 分含矿花岗伟晶岩脉和不含矿花岗伟晶岩脉[5] [6] [7]。 


\section{4. 矿致X苂光异常信息采集与成果图编制}

根据从已知到未知的原则, 为了采集到土壤中具有代表性的矿化花岗伟 晶岩脉的 X 苂光异常信息, 选择矿区已经探明的 5 号伟晶岩矿脉为研究对象, 按基本垂直花岗伟晶岩脉走向为原则, 在仁里矿区布置了三条测线 (见图 1), 依次为: P82、P44 和 P16, 测线长度分别为: $1600 \mathrm{~m} 、 1100 \mathrm{~m}$ 和 $1180 \mathrm{~m}$ 。 其中, P82 用于研究 46 与 5 号矿脉; P44 和 P16 则用于研究 5 矿脉。

根据花岗伟晶岩脉较窄的实际情况, 为了有效控制矿体可能形成的异常, $\mathrm{X}$ 苂光测线的测量基本点距采用 $20 \mathrm{~m}$, 重点区段加密至 $10 \mathrm{~m}$, 远离矿脉出露 区域则放宽至 $40 \mathrm{~m}$ 。

为了减少现场测量时土壤面存在的几何效应, 土壤 $\mathrm{X}$ 荧光测量工作采取 了取样后回野外驻地装杯测量的工作方法。每个测点的土壤样品, 按照地球 化学土壤测量规范, 采集自 $\mathrm{B}$ 层。根据试验, 这个深度约为 $30 \sim 40 \mathrm{~cm}$, 实际 工作中统一采用 $40 \mathrm{~cm}$ 采样深度。

土壤样品装杯后, 使用英国牛津公司生产的 X-MET7500 手持式 X 射线 苂光仪, 在土壤模式下进行测量, 每样的测量时间设置为 $80 \mathrm{~s}$ 。

根据实测获得的多元素的 $\mathrm{X}$ 苂光含量结果, 以各元素的含量 $(\mathrm{Nb}$ 元素与 $\mathrm{Y}$ 元素含量以峰面积表示)的 “祄度” 值(实测值与该元素的测区背景值之比) 为参数, 编制了 $\mathrm{X}$ 苂光多元素综合剖面图(图 2)与测区的平面剖面图(图 3)。

\section{5. 矿致X荧光异常特征研究}

以 P16 线多元素 X 苂光测量综合剖面图(图 2)为例, 探究矿区花岗伟晶岩 矿脉形成的 $\mathrm{X}$ 苂光异常的特征。

由图 2 可得, 所测量的元素中有多种元素在矿脉上方及附近出现了显著 的异常。其中 $\mathrm{K} 、 \mathrm{Rb} 、 \mathrm{Y} 、 \mathrm{Ta} 、 \mathrm{Nb} 、 \mathrm{Mn}$ 和 $\mathrm{Ca}$ 元素含量在矿脉上方及其附近 出现正异常, 尤其是 $\mathrm{K} 、 \mathrm{Rb} 、 \mathrm{Y} 、 \mathrm{Ta}$ 和 $\mathrm{Nb}$ 五种元素存在全线最高值, $\mathrm{Mn}$ 、 $\mathrm{Ca}$ 两元素虽出现正异常，但纵观全线其异常并无规律性； Fe、Ni、Sr、Zr 四 元素含量在矿脉上方及其附近出现明显负异常, 且存在全线最低值; $\mathrm{Cr} 、 \mathrm{~Pb}$ 和 $\mathrm{Zn}$ 三元素含量无明显异常。

为了总结出本勘查区花岗伟晶岩稀有金属矿的指示元素, 以 $\mathrm{Rb} 、 \mathrm{Ta}$ 和 $\mathrm{Nb}$ 三元素作为目标元素, 对所测得的元素进行 Pearson 相关分析 [8] [9](表 1)。 经 Pearson 相关分析得出: $\mathrm{Rb}$ 元素与 $\mathrm{K}$ 元素的相关系数为 $0.59, \mathrm{Rb}$ 元素与 $\mathrm{Y}$ 元素的相关系数为 $0.94, \mathrm{Rb}$ 元素与 $\mathrm{Fe}$ 元素的相关系数为 $-0.75, \mathrm{Rb}$ 元素与 $\mathrm{Ni}$ 元素的相关系数为 $-0.76, \mathrm{Rb}$ 元素与 $\mathrm{Sr}$ 元素的相关系数为 $-0.59, \mathrm{Rb}$ 元素 与 $\mathrm{Zr}$ 元素的相关系数为 $-0.93, \mathrm{Nb}$ 元素与 $\mathrm{Y}$ 元素的相关系数为 $0.78, \mathrm{Nb}$ 元 素与 $\mathrm{Fe}$ 元素的相关系数为 $-0.81, \mathrm{Nb}$ 元素与 $\mathrm{Ni}$ 元素相关系数为 $-0.58, \mathrm{Nb}$ 元素与 $\mathrm{Zr}$ 元素的相关系数为 $-0.62, \mathrm{Ta}$ 元素与 $\mathrm{Y}$ 元素的相关系数为 $0.53, \mathrm{Ta}$ 元素与 $\mathrm{Zr}$ 元素的相关系数为 -0.54 。

由以上分析和 $\mathrm{Rb} 、 \mathrm{Ta}$ 和 $\mathrm{Nb}$ 元素的地球化学特征结合花岗伟晶岩稀有金 属矿特性, 可以得出勘查区花岗伟晶岩稀有金属矿的指示元素为 $\mathrm{Rb} 、 \mathrm{Nb}$ 、 $\mathrm{Ta} 、 \mathrm{Y} 、 \mathrm{Fe} 、 \mathrm{Ni} 、 \mathrm{Sr}$ 和 $\mathrm{Zr}$ 。为了更准确直观的掌握仁里矿区花岗伟晶岩稀有 


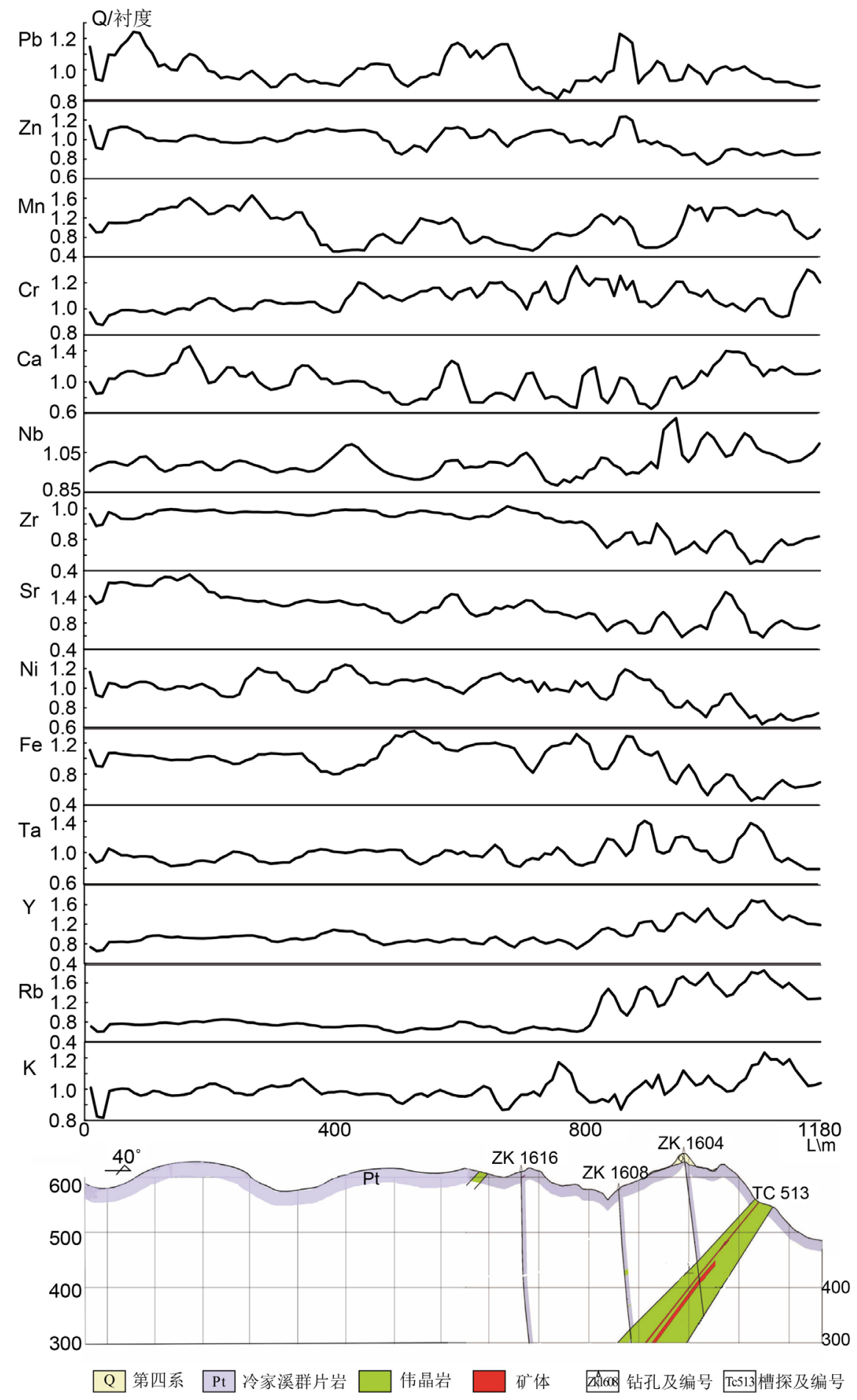

图 2. P16 线多元素综合剖面图

金属矿的土壤 X 苂光特征, 根据上述结论绘制了异常元素累加比值图, 以正 异常显著的 $\mathrm{Rb} 、 \mathrm{Nb} 、 \mathrm{Ta}$ 和 $\mathrm{Y}$ 四元素含量的累加值除以负异常显著 $\mathrm{Fe} 、 \mathrm{Ni}$ 、 $\mathrm{Sr}$ 和 $\mathrm{Zr}$ 四元素含量的累加值(图 3)。

由图 3 可以看出, 在矿脉上方及矿脉出露点附近累加比值异常显著, 其 异常幅度范围在 1.06 3.07 之间, 平均值为 1.73 。为了进一步论证仁里矿区花 


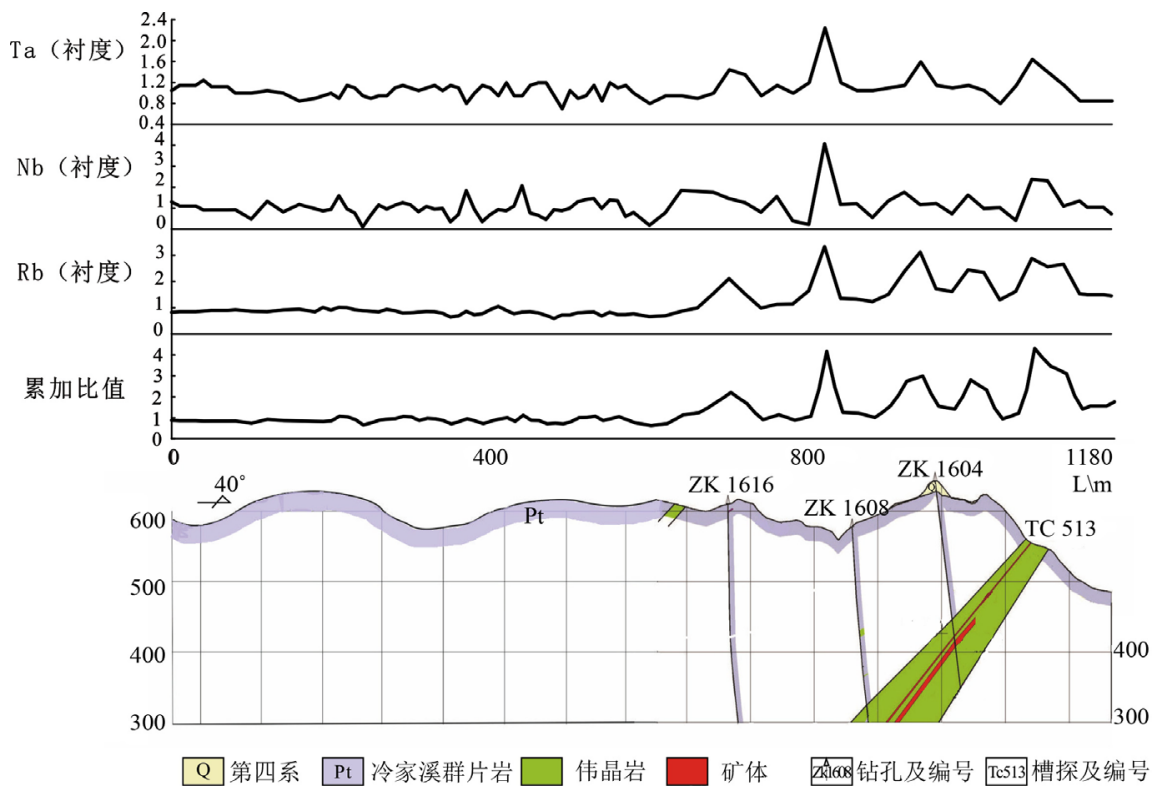

图 3.P16 线目标元素及累加比值剖面图

表 1. Pearson 相关系数表

\begin{tabular}{cccc}
\hline Pearson 相关性 & $\mathrm{Rb}$ & $\mathrm{Ta}$ & $\mathrm{Nb}$ \\
\hline $\mathrm{K}$ & 0.59 & 0.27 & 0.43 \\
$\mathrm{Ca}$ & 0.29 & -0.16 & -0.03 \\
$\mathrm{Cr}$ & 0.05 & -0.02 & -0.01 \\
$\mathrm{Mn}$ & 0.28 & -0.13 & 0.03 \\
$\mathrm{Fe}$ & -0.75 & -0.22 & -0.44 \\
$\mathrm{Ni}$ & -0.76 & -0.13 & -0.44 \\
$\mathrm{Zn}$ & -0.63 & -0.04 & -0.22 \\
$\mathrm{Rb}$ & 1.00 & 0.49 & 0.52 \\
$\mathrm{Sr}$ & -0.59 & -0.46 & -0.41 \\
$\mathrm{Zr}$ & -0.93 & -0.54 & -0.53 \\
$\mathrm{Ta}$ & 0.49 & 1.00 & 0.48 \\
$\mathrm{~Pb}$ & -0.15 & 0.06 & -0.18 \\
$\mathrm{Y}$ & 0.94 & 0.53 & 0.54 \\
$\mathrm{Nb}$ & 0.52 & 0.48 & 1.00 \\
\hline
\end{tabular}

岗伟晶岩稀有金属矿的土壤 X 苂光异常特征, 绘制出三条测线的异常元素累 加比值平面剖面图(图 4)。

通过图 4 可以看出: 在 P82 和 P44 测线上, 矿脉上方及出露点附近土壤 $\mathrm{X}$ 荧光异常特征也非常显著。其中 P82 线异常幅度范围在 1.19 1.91 之间, 平 均值为 1.49 , P44 线异常幅度范围在 1.05 1.86 之间, 平均值为 1.45 。对于 P82 线上的 46 号脉, 及 $\mathrm{P} 16$ 线上的西南部另一处花岗伟晶岩脉, 可能由于埋藏深 度和地形等因素的原因, 虽略有异常, 但其异常幅度不如 2 号脉和 5 号脉上 


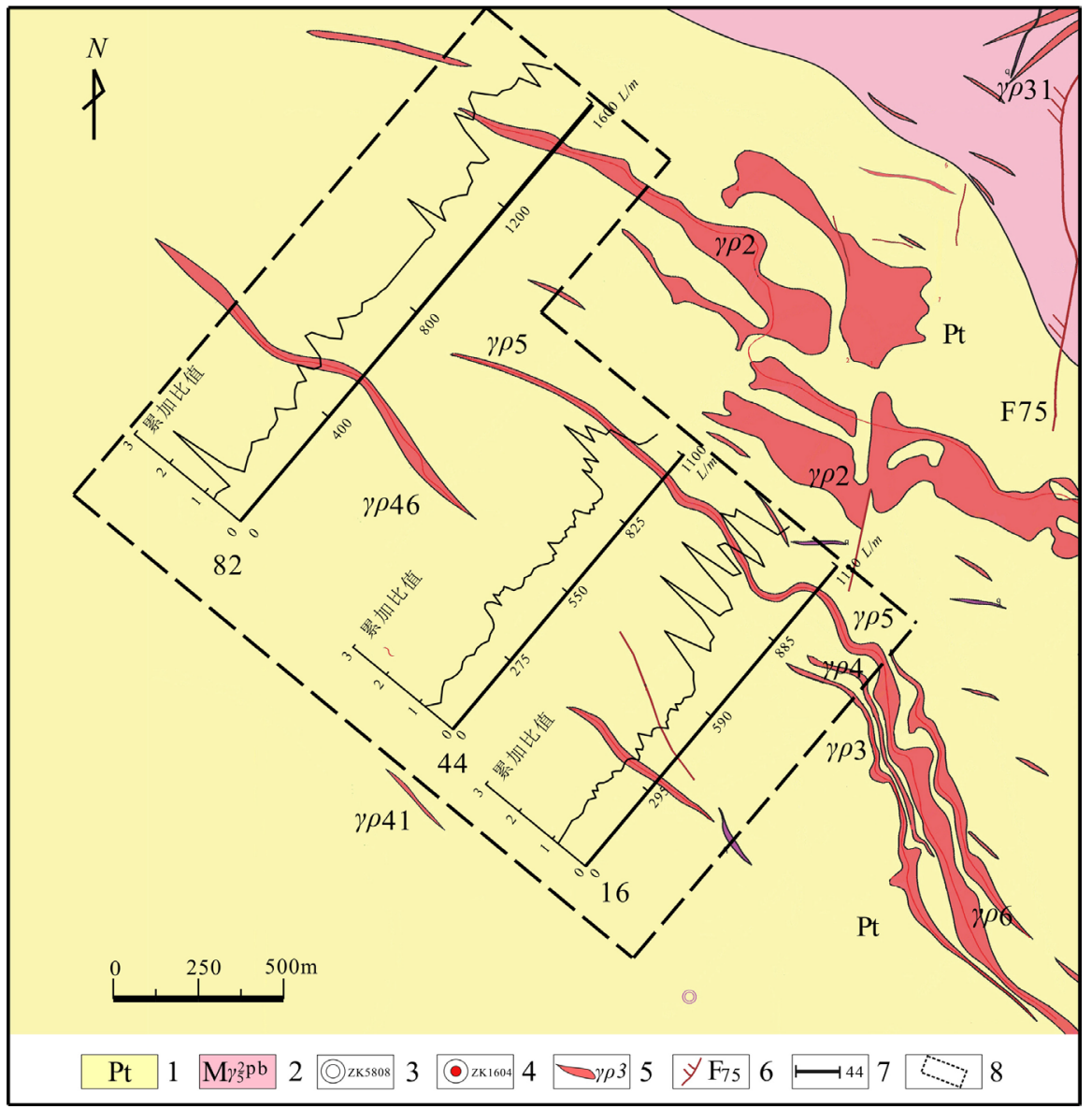

1. 元古宙冷家溪群片岩; 2. 粗中粒似斑状黑云母二长花岗岩; 3. 钻孔及其编号; 4. 伟晶岩脉及 其编号； 5. 断裂及其编号； 6. 测线及其编号; 7. 工作区域。

\section{图 4. 仁里矿区异常元素累加比值平面剖面图}

显著。

综上所述，在仁里花岗伟晶岩稀有金属矿的指示元素为: $\mathrm{Rb} 、 \mathrm{Nb} 、 \mathrm{Ta}$ 、 $\mathrm{Y}, \mathrm{Fe} 、 \mathrm{Ni} 、 \mathrm{Sr}$ 和 $\mathrm{Zr}$ 。仁里花岗伟晶岩稀有金属矿土壤 $\mathrm{X}$ 荧光矿化特征, 可 由指示元素的累加比值幅度表示。在元素组分上: $\mathrm{Rb} 、 \mathrm{Nb} 、 \mathrm{Ta}$ 三元素均与 $\mathrm{Y}$ 元素有着良好的相关性。

在 P44 线西南部存在一个未知异常区段 (未知异常 I), 其异常幅度范围在 1.15 1.36 之间, 平均值为 1.23, 下方并不存在已勘查矿体, 但其西北方向有 已勘查的 46 号脉, 东南方向也存在已勘查矿脉, 异常特征幅度范围介于上文 矿脉上方异常特征幅度范围, 所以下方可能存在隐伏矿体, 是寻找花岗伟晶 岩稀有金属矿的有利找靶矿区。

\section{6. 结论}

通过在仁里矿区开展的三条测线土壤 $\mathrm{X}$ 苂光采样及测量工作, 综合运用 异常剖面图和应用多元统计方法分析测量结果, 详细研究了伟晶岩稀有金属 矿 $\mathrm{X}$ 荧光异常的元素组合特征、异常幅度和空间分布特征, 得出以下三点认 识: 
1) 对于已知矿区的分析, 可知仁里花岗伟晶岩稀有金属矿的 $\mathrm{X}$ 苂光异常 特征为 $K 、 R b 、 N b 、 T a$ 和 $Y$ 五元素出现明显正异常, $\mathrm{Fe} 、 \mathrm{Ni} 、 \mathrm{Sr}$ 和 $\mathrm{Zr}$ 四元 素出现明显负异常。结合多元统计的相关分析, Rb、Nb、Ta、Y、Fe、 Ni、 $\mathrm{Sr}$ 和 $\mathrm{Zr}$ 可作为该区域的指示(矿)元素。在元素组分上 $\mathrm{Rb} 、 \mathrm{Nb} 、 \mathrm{Ta}$ 三元素均 与 $\mathrm{Y}$ 元素有着良好的相关性。由指示元素建立的土壤 $\mathrm{X}$ 荧光异常特征适用于 仁里矿区的找矿工作。由于 $\mathrm{X}$ 苂光测量主要反映地表浅层矿床异常特征, 对 于深部隐伏矿床还需借助多种物化探方法共同建立其特征模式。

2) P44 线西南部的未知异常区段下方可能存在隐伏矿体, 且与其西北的 46 号脉和东南的矿脉相连, 是找花岗伟晶岩稀有金属矿的有利找靶矿区。

3) 通过建立的花岗伟晶岩稀有金属矿化特征模式, 手持式 $X$ 射线苂光仪 能够适用于花岗伟晶岩稀有金属矿的现场快速准确测定。

\section{Conflicts of Interest}

The author declares no conflicts of interest regarding the publication of this paper.

\section{References}

[1] 陈虎, 陈阶然, 周芳春, 等. 湖南仁里铌钽矿床地质特征及找矿标志 $[\mathrm{J}]$. 国土资 源导刊, 2018, 15(4): 76-81.

[2] 刘翔, 周芳春, 李健康, 等. 湖南平江县仁里超大型伟晶岩型铌钽多金属矿床的 发现及其意义[J]. 大地构造与成矿学, 2018, 42(2): 235-243.

[3] 王盘喜, 包民伟. 我国铌钽等稀有金属矿概况及找矿启示 [J]. 金属矿山, 2015, 6(1): 92-97.

[4] 赵伦山, 张本仁. 地球化学 $[\mathrm{M}]$. 北京: 地质出版社, 1988.

[5] 刘俊, 周四春, 刘国安, 等. 多元素 $X$ 苂光方法在湖北某铀矿区中的应用[J]. 现 代矿业, 2013(9): 65-69.

[6] 吴丽荣, 周四春, 吕少辉, 等. 多元素 $\mathrm{X}$ 苂光测量技术在某金矿外围找矿中的应 用[J]. 金属矿山, 2010(10): 90-94.

[7] 周四春, 谢庭周, 葛良全, 等. $X$ 苂光勘查金矿技术的应用与进展 [J]. 物探化探计 算技术, 1996, 8(18): 66-69.

[8] 郭科, 龚影. 多元统计方法及其应用 $[M]$. 成都: 电子科技大学出版社, 2003 .

[9] 李正文, 何振华. 勘查技术工程学[M]. 北京: 地质出版社, 2002. 


\section{Appendix (Abstract and Keywords in Chinese)}

\section{湖南仁里花岗伟晶岩稀有金属矿 $\mathrm{X}$ 荧光异常特征及意义}

摘要: 在湖南平江县仁里花岗伟晶岩铌钽稀有金属矿区, 在三条穿越已 知矿脉的测线上应用手持式 $\mathrm{X}$ 苂光仪开展了土壤多元素 $\mathrm{X}$ 苂光测量, 研究了 矿致 X 苂光异常的元素组合、幅度、以及矿致异常与矿体的空间关联关系。 结果表明, 含矿脉出露处或出露投影处上方存在 $\mathrm{K} 、 \mathrm{Nb} 、 \mathrm{Ta} 、 \mathrm{Rb} 、 \mathrm{Y}$ 的正异 常, $\mathrm{Fe} 、 \mathrm{Ni} 、 \mathrm{Zn} 、 \mathrm{Zr}$ 的负异常(或低值区)。因此, 可以将目标元素 $\mathrm{Nb} 、 \mathrm{Ta}$ 、 $\mathrm{Rb}$ 的 X 苂光异常, 与 $(\mathrm{Nb}+\mathrm{Ta}+\mathrm{Rb}+\mathrm{Y}) /(\mathrm{Fe}+\mathrm{Ni}+\mathrm{Sr}+\mathrm{Zr})$ 的多元素 $\mathrm{X}$ 苂光 累加比值异常作为快速评价花岗伟晶岩脉含矿性的依据。

关键词: 花岗伟晶岩, 稀有金属矿, $\mathrm{X}$ 苂光测量, 异常特征, 找矿意义 